\title{
A high-strength heterogeneous structural dual-phase steel
}

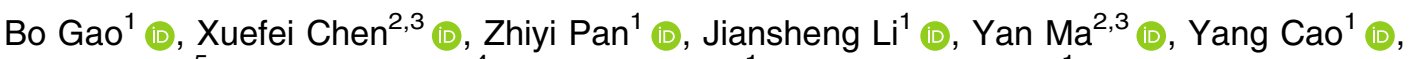 \\ Manping $\mathrm{Liu}^{5}$ (D), Qingquan $\mathrm{Lai}^{4, \star}$ (1), Lirong Xiao ${ }^{1, \star}$ (D), and Hao Zhou ${ }^{1}$ (D) \\ ${ }^{1}$ Nano and Heterogeneous Materials Center, School of Materials Science and Engineering, Nanjing University of Science and \\ Technology, Nanjing 210094, China \\ ${ }^{2}$ State Key Laboratory of Nonlinear Mechanics, Institute of Mechanics, Chinese Academy of Sciences, Beijing 100190, China \\ ${ }^{3}$ School of Engineering Science, University of Chinese Academy of Sciences, Beijing 100049, China \\ ${ }^{4}$ Herbert Gleiter Institute of Nanoscience, Nanjing University of Science and Technology, Nanjing 210094, China \\ ${ }^{5}$ School of Materials Science and Engineering, Jiangsu University, Zhenjiang 212013, China
}

Received: 20 February 2019

Accepted: 23 June 2019

Published online:

1 July 2019

(C) Springer Science+Business Media, LLC, part of Springer Nature 2019

\begin{abstract}
The strengthening and ductilization of steels are of great importance to weight reduction of vehicles. In this work, the strength-ductility synergy of dual-phase (DP) steels was obtained by properly tailoring the structural heterogeneity, including the distribution and fraction of constituent phases. It was demonstrated that heterogeneous structural DP steels with high volume fraction of martensite (from 64 to $83 \%$ ) led to a good combination of strength and ductility. Compared with the cold-rolled sheets, the tensile strength and uniform elongation of heterogeneous DP steel increased by $700 \mathrm{MPa}$ (from 1.06 to $1.76 \mathrm{GPa}$ ) and $2.7 \%$ (from 1.3 to $4 \%$ ), respectively. The contributions from back stress and effective stress were analyzed by cyclic loading-unloading experiments. The underlying deformation mechanism was discussed based on the results of mechanical test and microstructure observation.
\end{abstract}

\section{Introduction}

Due to the upcoming crisis in environmental pollution and energy source exhaustion, environmental protection and energy efficiency are becoming the main driving forces for the development of novel high-strength metallic materials in the automobile industry [1, 2]. Lightweight alloys, such as aluminum alloys and magnesium alloys, are widely applied in vehicles, which have definite benefits for saving energy. However, the safety of vehicle is still supported by steel alloys which have excellent capability in absorbing energy to prevent catastrophic failure during service [3]. Yet, the combination of the strength and ductility/toughness has to be improved to meet the increasingly stringent design requirements, and novel approaches and concepts of microstructure engineering are heavily needed to sustain the alloy development.

Address correspondence to E-mail: lai@njust.edu.cn; xiaolr620@126.com 
The heterogeneities of the materials at various scales have received much attention due to the potential of attaining impressive mechanical properties. The relevant heterogeneities include the gradient structure [4], bimodal structure [5], dual-phase (DP) steel [6-8], heterogeneous lamella structure [9] and nanodomained structure [10]. These materials all have a dramatic difference in strength between different domains, while the sizes and geometry of the domains could be in the range of micrometers to millimeters, and have been defined as heterogeneous structural materials (HSMs) [11]. The mechanical heterogeneity can be induced by microstructural heterogeneity or compositional heterogeneity. Due to the significant strength mismatch between different domains in HSMs, inhomogeneous deformation occurs in the local areas, leading to a strain gradient around the interfaces [11, 12]. The strain gradient is accommodated by building up geometrically necessary dislocations (GNDs) [11, 13, 14]. In addition, the stress partitioning could occur within different domains (e.g., grains with wide distribution of diameter [15]). Both the generation of GNDs and the stress partitioning within different domains result in the long-range back stress to resist monotonic deformation [9]. Recently, it is proposed that the ideal structure in the HSMs is that the soft domains are completely surrounded by the hard domain matrix so that the soft domains cannot change their shape as required by plastic deformation until the hard domains matrix start to deform [11]. In this case, the generation of GNDs is enhanced and the resulting back stress makes the soft domains almost as strong as the hard domains, leading to the macroscopic yield strength much higher than what is predicted by the rule of mixture. In addition, the back stress work hardening will also help with preventing necking during tensile testing, thus improving ductility $[11,16]$. $\backslash$

Steel composed of different phases is a kind of natural HSMs, in which the phases have different mechanical properties [17-21]. For example, the commercial DP steels, generally containing 20-30 vol\% hard martensite phase embedded in the soft ferrite matrix [22-24], have been paid continuous attention due to their attractive mechanical properties, including the strength-ductility synergy, good formability and low production cost [25-28]. Compared with other HSMs reported in the literature $[4,5,9,10]$, the production of DP steels is more flexible, involving the interplay of alloy composition and the controlled genesis of microstructure [25]. The carbon content plays a dominant role in controlling the volume fraction and hardness of martensite in DP steels. The other alloying elements, such as Mn and $\mathrm{Si}$, influence the recrystallization processes and the hardenability during quenching. In addition, the interaction between phase transformation and recrystallization-related phenomena provides plenty of possibilities to manipulate the structural scale, the distribution and percolation of strong phase and the strength contrast between phases $[29,30]$. The flexibility of processing of the DP steels provides the opportunity to examine the mechanical properties of HSMs with high volume fraction of strong phase, especially for the case that the soft ferrite is surrounded by strong martensite. Such model microstructure, different from the conventional DP steels, has been produced in a low carbon-manganese steel in this work. The structural evolution during tension was characterized using transmission electron microscope (TEM, TECNAI 20). The mechanical properties were measured by uniaxial tension. Cyclic loading-unloading experiments were performed to measure the magnitude of Bauschinger effect, probing the strengthening mechanism and the role of heterogeneity.

\section{Experimental materials and procedures}

The material used in this work is a cold-rolled plate of low carbon-manganese steel $(0.22 \mathrm{C}, 1.16 \mathrm{Si}$ and $1.7 \mathrm{Mn}$ in wt\%) with a thickness of $1.6 \mathrm{~mm}$. Intercritical annealing was carried out, respectively, at four temperatures $\left(780{ }^{\circ} \mathrm{C}, 800{ }^{\circ} \mathrm{C}, 820^{\circ} \mathrm{C}\right.$ and $\left.840{ }^{\circ} \mathrm{C}\right)$ for $8 \mathrm{~min}$ and then was quenched into water to obtain the DP structure. The critical temperatures of phase transformation were evaluated according to the equations in Refs. [31, 32], and the temperatures of $A_{1}$ and $\mathrm{A}_{3}$ were $743{ }^{\circ} \mathrm{C}$ and $894{ }^{\circ} \mathrm{C}$, respectively. Since the initial microstructure was in the deformed state, the intercritical annealing involved both the austenite formation and recrystallization and grain growth of ferrite. A long annealing time could result in abnormal grain growth, while a short annealing was not sufficient for austenite formation [33, 34]. In the previous study, we found that the annealing for $8 \mathrm{~min}$ is appropriate for austenite formation, when the microstructural scale was maintained. The dog- 
bone tensile specimens with a gauge length of $10 \mathrm{~mm}$ and width of $2.5 \mathrm{~mm}$ were cut from the steel plates with longitudinal axes parallel to the rolling direction. All tensile specimens were mechanically polished prior to tensile tests. The quasi-static uniaxial tensile tests were performed in a LTM-20KN testing machine with a strain rate of $3 \times 10^{-3} \mathrm{~s}^{-1}$ at ambient temperature. The cyclic loading-unloading tests were carried out by using a MTS Landmark testing machine. Upon straining to an assigned value, the specimen was unloaded to $50 \mathrm{~N}$ at the same strain rate, followed by reloading at the strain rate of $1 \times 10^{-3} \mathrm{~s}^{-1}$ to the same applied stress before the next unloading.

To characterize the microstructure, the samples in transverse section were ground and mechanically polished. The polished surfaces were etched with a 5\% Nital solution. The etched samples were observed by optical microscope (OM, Olympus BX41 M) and scanning electron microscope (SEM, FEI Quanta 250F). The volume fraction of martensite was analyzed by using the image processing software (Image $\mathrm{J})$ on the SEM images, following the procedure in ref [25]. X-ray diffraction (XRD, Bruker D8) was utilized for phase identification after annealing. The 2-Theta angle ranged from $40^{\circ}$ to $100^{\circ}$ using a scanning speed of $6 \% \mathrm{~min}$. The substructures of DP steels were characterized by TEM operated at $200 \mathrm{kV}$. The TEM foils were cut parallel to the normal plane and thinned to a thickness of $\sim 60 \mu \mathrm{m}$ by grinding. Finally, the foils were thinned by a twin-jet polishing facility using a solution of $20 \%$ perchloric acid and $80 \%$ methanol at $-35{ }^{\circ} \mathrm{C}$.

\section{Results and discussion}

\section{Microstructures}

Cold-rolled ferrite-pearlite steel with a thickness reduction of $\sim 90 \%$ was used as the starting material. Figure 1a shows a three-dimensional reconstruction of the starting microstructure along normal direction (ND), rolling direction (RD) and transverse direction (TD), respectively. Viewing from $\mathrm{RD}$ and $\mathrm{TD}$, the lamellar structure composed of ferrite and pearlite is observed. The SEM image (Fig. 1b) shows that the thickness of alternating ferrite and pearlite layers is $\sim 1 \mu \mathrm{m}$. Owing to the severe rolling deformation, some of the pearlite colonies were broken into multiple segments as shown in Fig. 1b. The ferrite grains are obviously elongated along the rolling direction. Figure 1c, $d$ shows the TEM images of the ferrite grains exhibiting a very high dislocation density. The discontinuous rings in selected area electron diffraction (SAED) pattern indicate that the ferrite grains are divided into several nano-sized dislocation cells with low-angle misorientation.

In order to obtain different volume fractions of martensite in the DP steels, intercritical annealing was carried out at $780{ }^{\circ} \mathrm{C}, 800{ }^{\circ} \mathrm{C}, 820^{\circ} \mathrm{C}$ and $840{ }^{\circ} \mathrm{C}$, respectively. When intercritically annealed at $780{ }^{\circ} \mathrm{C}$ (Fig. 2a), the lamellar structure in as-rolled steel almost disappears except that some ferritic grains remain elongated. It is found that most of the martensite grains are distributed around the ferrite grains. Meanwhile, there are a few intragranular martensite islands of the size less than $1 \mu \mathrm{m}$. The martensitic phase is obtained by quenching the austenite from high temperature. The corner and edge of ferrite grains are the preferred sites for nucleation of austenite [35, 36]. Owing to the restriction of surrounding martensite grains, the grain growth of ferrite was limited during the annealing. Meanwhile, the volume fraction of martensite is increased with increasing temperature, associating with a decrease of ferrite grain size as shown in Fig. $2 b-d$. The XRD results show that only the peaks for bcc phase can be found (Fig. 2e), indicating that the amount of retained austenite is negligible. By quantifying the micrographs, the volume fractions of martensite in the DP steels were estimated as shown in Fig. 2f. It shows that the volume fraction of martensite $\left(V_{\mathrm{m}}\right)$ increases from 64 to $83 \%$ as the annealing temperature increases from 780 to $840{ }^{\circ} \mathrm{C}$. Consequently, the carbon content $\left(C_{\mathrm{m}}\right)$ of martensite calculated by the following Eq. (1) [37] exhibits a descending trend, as shown in Fig. 2f.

$C_{\mathrm{m}}=\frac{C-C_{\mathrm{f}} *\left(1-V_{\mathrm{m}}\right)}{V_{\mathrm{m}}}$,

where $C$ and $C_{\mathrm{f}}$ represent the carbon content of the steel and ferrite, respectively. The value of $C_{\mathrm{f}}$ is set as 0.015 which is the supersaturated limit of carbon in ferrite [37].

Two kinds of ferrite morphologies can be observed in the intercritically annealed DP steels. One is the larger-sized ferritic grains $(>5 \mu \mathrm{m})$ obtained at lower temperatures (annealed at $780{ }^{\circ} \mathrm{C}$ and $800{ }^{\circ} \mathrm{C}$ ) with some intragranular martensite islands, and the other 

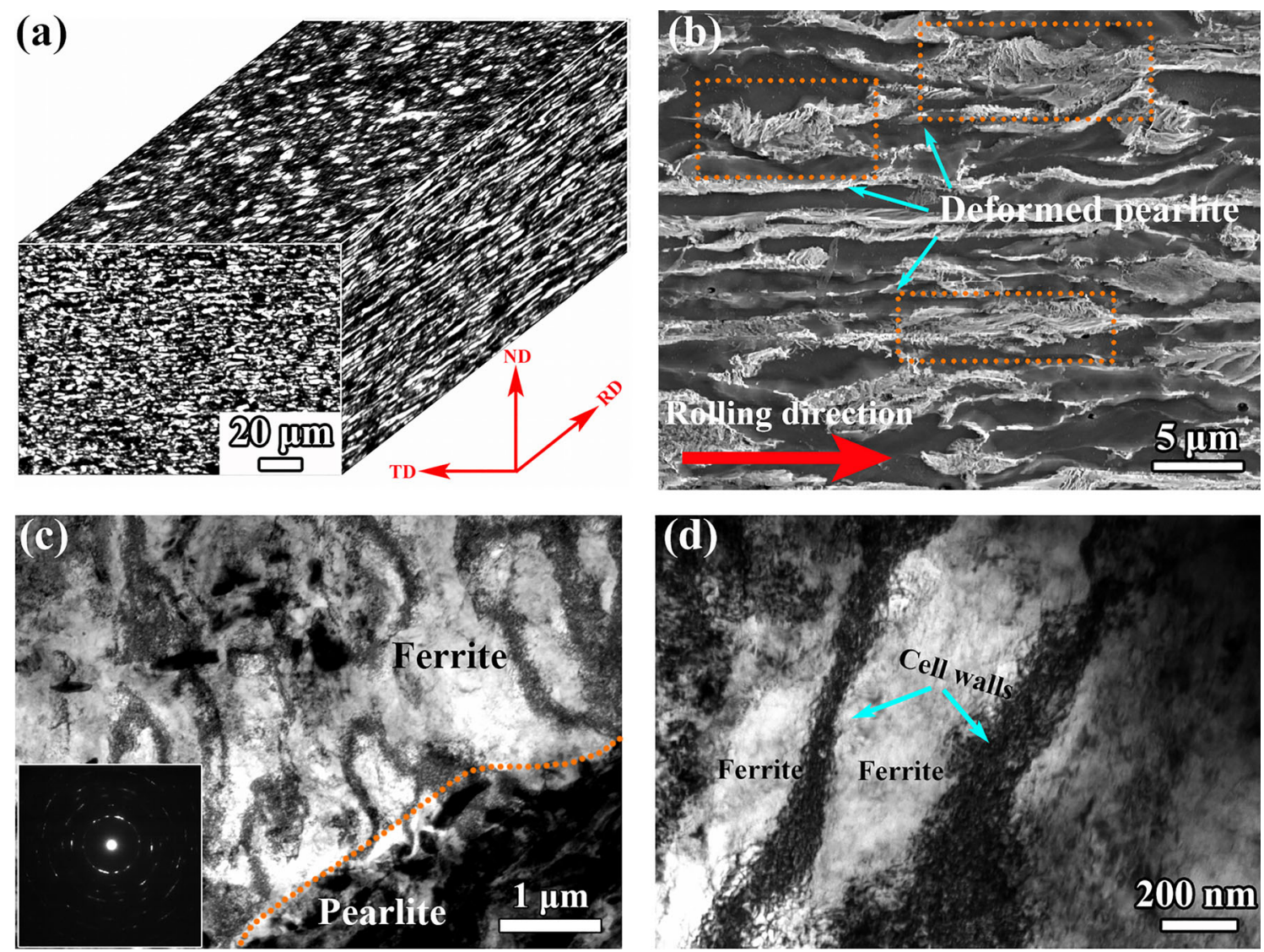

Figure 1 Microstructure of cold-rolled ferrite-pearlite steel: a three-dimensional optical micrograph; $\mathbf{b}$ SEM image in transverse section; c, $\mathbf{d}$ bright-field TEM images and SAED pattern of ferrite grains.

is the smaller-sized ferritic grains $(\sim 1 \mu \mathrm{m})$, embedding in the martensite matrix, obtained at higher temperatures (annealed at $820^{\circ} \mathrm{C}$ and $840{ }^{\circ} \mathrm{C}$ ). The samples annealed at $780{ }^{\circ} \mathrm{C}$ and $820{ }^{\circ} \mathrm{C}$ (simplified by DP-780 and DP-820) were observed by TEM to comparatively study the detailed microstructure evolution during deformation within ferrite grains, including the dislocation multiplication and pile-up. And in order to reveal the distribution of the dislocations in ferrite during deformation, the two-beam condition of $g=[01 \overline{1}]$, which can be set by tilting the specimen slightly from the [111] zone axis, was employed. Different two-beam conditions result in different visibility (dislocations are visible as $g \cdot \underline{b} \neq$ 0 ) for dislocations. Assuming all dislocations having Burgers vectors of $a / 2$ [111], where $a$ is the lattice parameter of ferrite, the diffraction condition of $g=$ [200] leads to full appearance of dislocations; under the diffraction condition of $g=[01 \overline{1}]$, only half of the dislocations will appear. In order to make dislocations distinct even at a high engineering strain condition, the two-beam condition of $g=[01 \overline{1}]$ was employed. As shown in Fig. 3a and b, the ferrite grain with the size of $5 \mu \mathrm{m}$ is surrounded by martensite. There are also some small intragranular martensite islands with the width ranging from 0.2 to $1 \mu \mathrm{m}$. Dislocations of low density are distributed uniformly within the ferrite grain as shown in Fig. 3b. It has been reported that the unpinned dislocations in the deformation of adjacent ferrite were created due to the phase transformation during quenching $[38,39]$. Corresponding microstructure schematic of the DP-780 sample is shown in Fig. 3c. Viewing in the same two-beam condition, the DP-820 sample shows a different microstructure as shown in Fig. 3d, e. It is found that a few ferrite grains with the size of less than $1 \mu \mathrm{m}$ are embedded in the martensite matrix in DP-820 sample. Dislocations in these fine ferrite grains are also uniformly distributed, which is similar as the DP-780 sample.

Figure 4 shows TEM micrographs of DP-780 and DP-820 after a $4 \%$ tensile deformation. The 

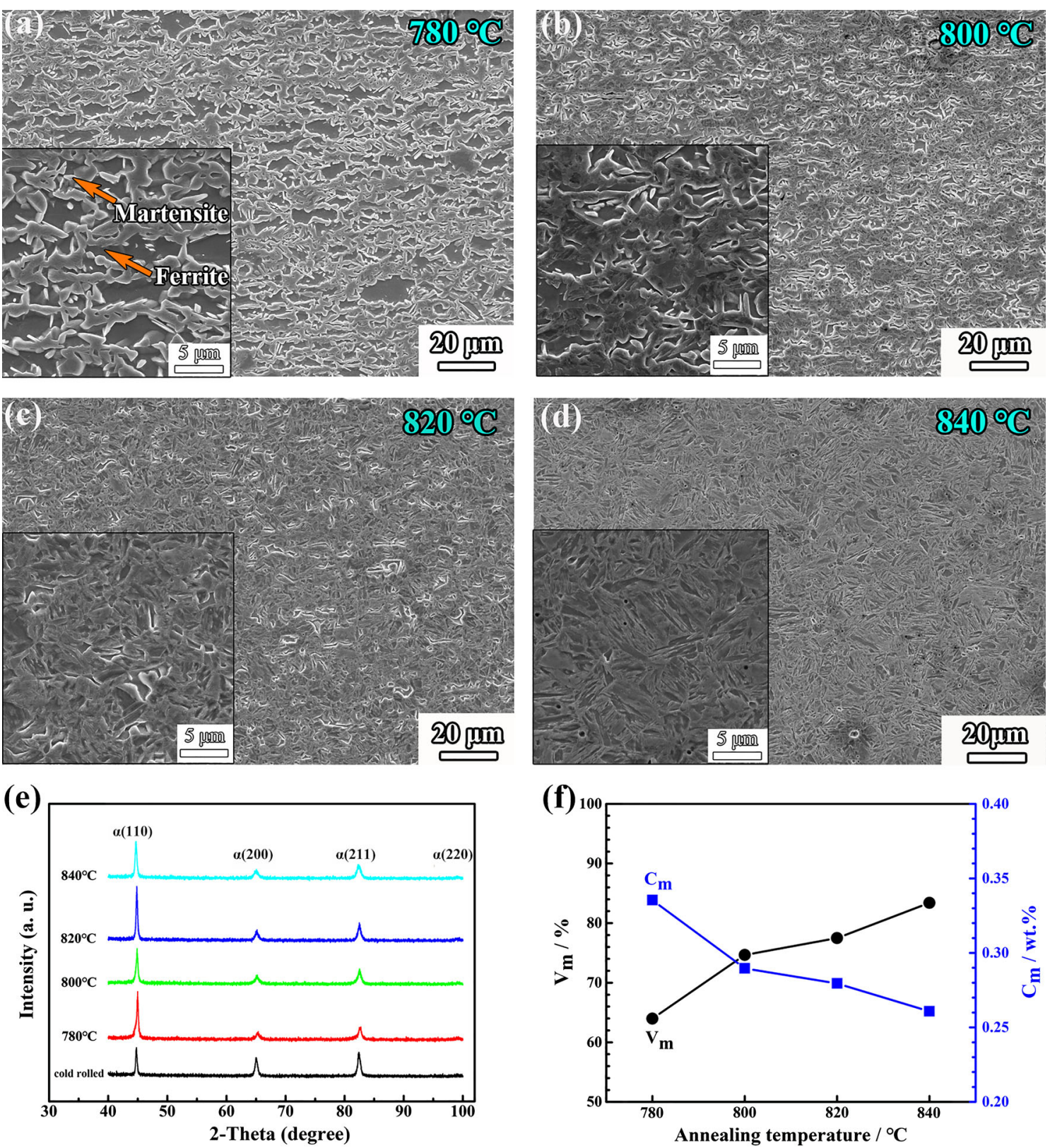

Figure 2 SEM images of DP steels annealed at different temperatures: a $780{ }^{\circ} \mathrm{C}$; b $800{ }^{\circ} \mathrm{C}$; c $820{ }^{\circ} \mathrm{C}$; and $\mathbf{d} 840{ }^{\circ} \mathrm{C}$; e XRD patterns of cold-rolled steel and DP steels annealed at

observation of TEM was carried out under the same two-beam condition as for the undeformed samples in Fig. 3. Significant increase of dislocation density is found in both the DP-780 and the DP-820 samples. This is consistent with the structural evolution during deformation in most HSMs, in which the "soft" phase in materials contributes to the main plastic deformation [9, 11]. A number of dislocations were observed to pile up around the martensite islands in DP-780 samples (Fig. 4a, b), which is also illustrated

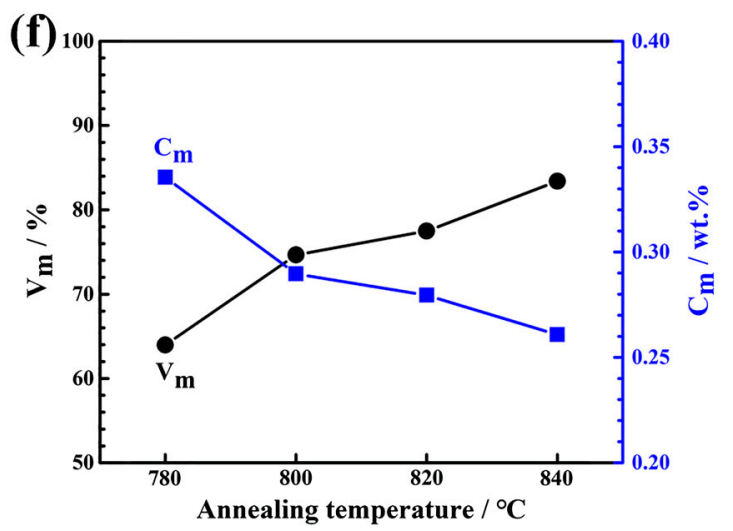

different temperatures; $\mathbf{f}$ volume fraction $\left(V_{\mathrm{m}}\right)$ and carbon content $\left(C_{\mathrm{m}}\right)$ of martensite in the annealed DP steels.

in Fig. 4c that the dislocation in ferrite cannot transmit across the intragranular martensite islands so that they pile up around them. In the small-sized ferrite with few martensite islands of DP-820, dislocation accumulated uniformly as illustrated in Fig. 4f. With increasing $V_{\mathrm{m}}$, ferrite grain size decreased. However, it is still the soft regions when comparing with the martensite phase. Therefore, the small ferrite grains still contribute significantly to the plastic strain, while the constraint of the surrounding martensite

\section{Springer}



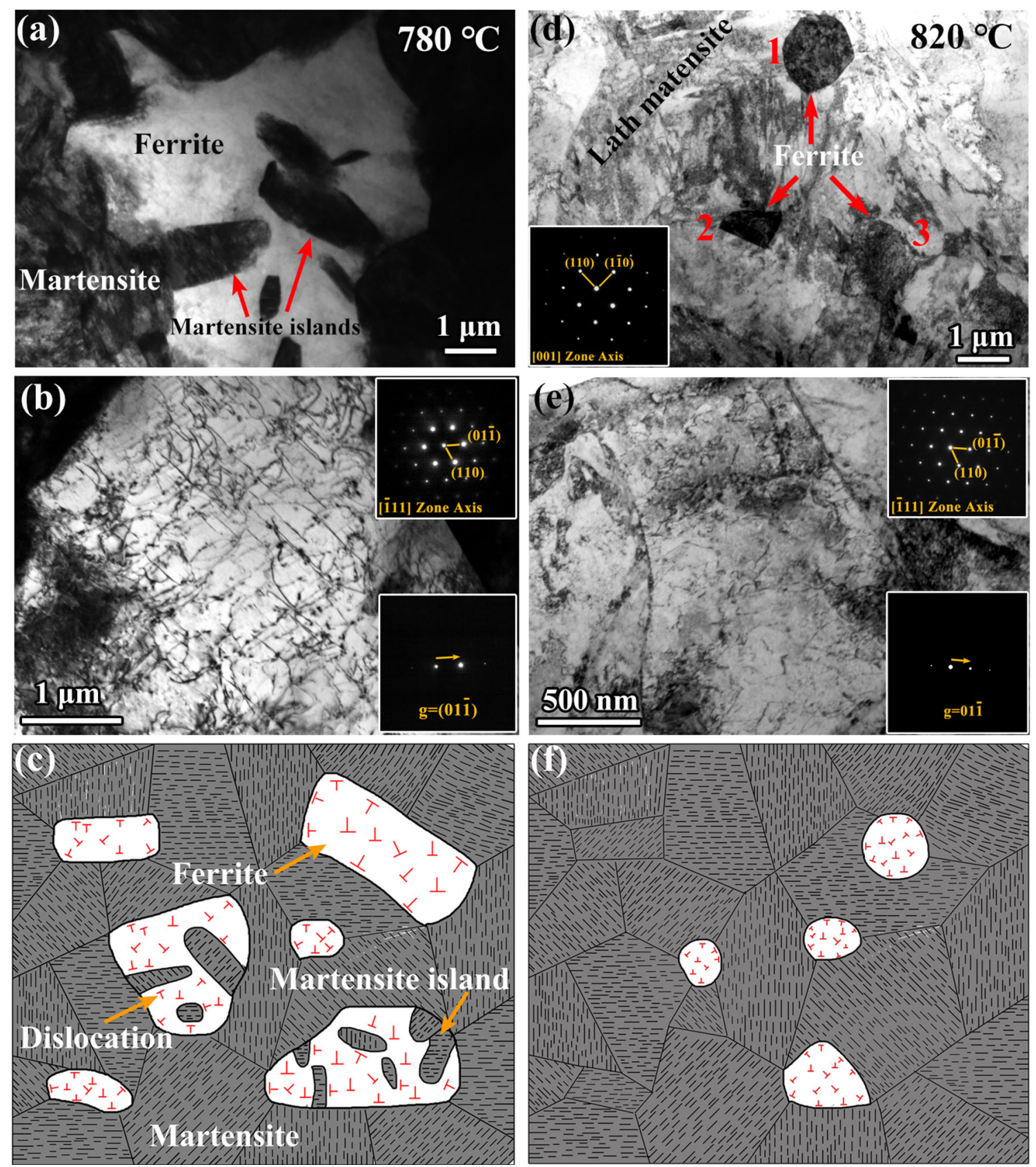

Figure 3 Microstructure of the DP-780 and DP-820 samples: a bright-field TEM image of DP-780; $\mathbf{b}$ bright-field TEM image viewed in a two-beam condition of $g=[01 \overline{1}]$; and $\mathbf{c}$ the corresponding schematic diagram; $\mathbf{d}$ bright-field TEM image of

enhanced the generation of GNDs and thus the strain hardening $[9,25]$.

\section{Mechanical properties}

As illustrated in Fig. 5a, the DP steels with different volume fractions of martensite were prepared by the

DP-820, the inset image is the selected area electron diffraction pattern of ferrite grain 1; e bright-field TEM images viewed in a two-beam condition of $g=[01 \overline{1}]$, and $\mathbf{f}$ the corresponding schematic diagram.

intercritically annealing at different temperatures. Figure $5 \mathrm{~b}$ shows the engineering stress-strain $(\sigma-\varepsilon)$ curves of all the DP steels, comparing also with the cold-rolled ferrite-pearlite steel which exhibits an ultimate tensile stress (UTS) of 1 GPa with very limited uniform elongation $(\sim 1.3 \%)$. Cold rolling is a common way to produce high-strength steel by 

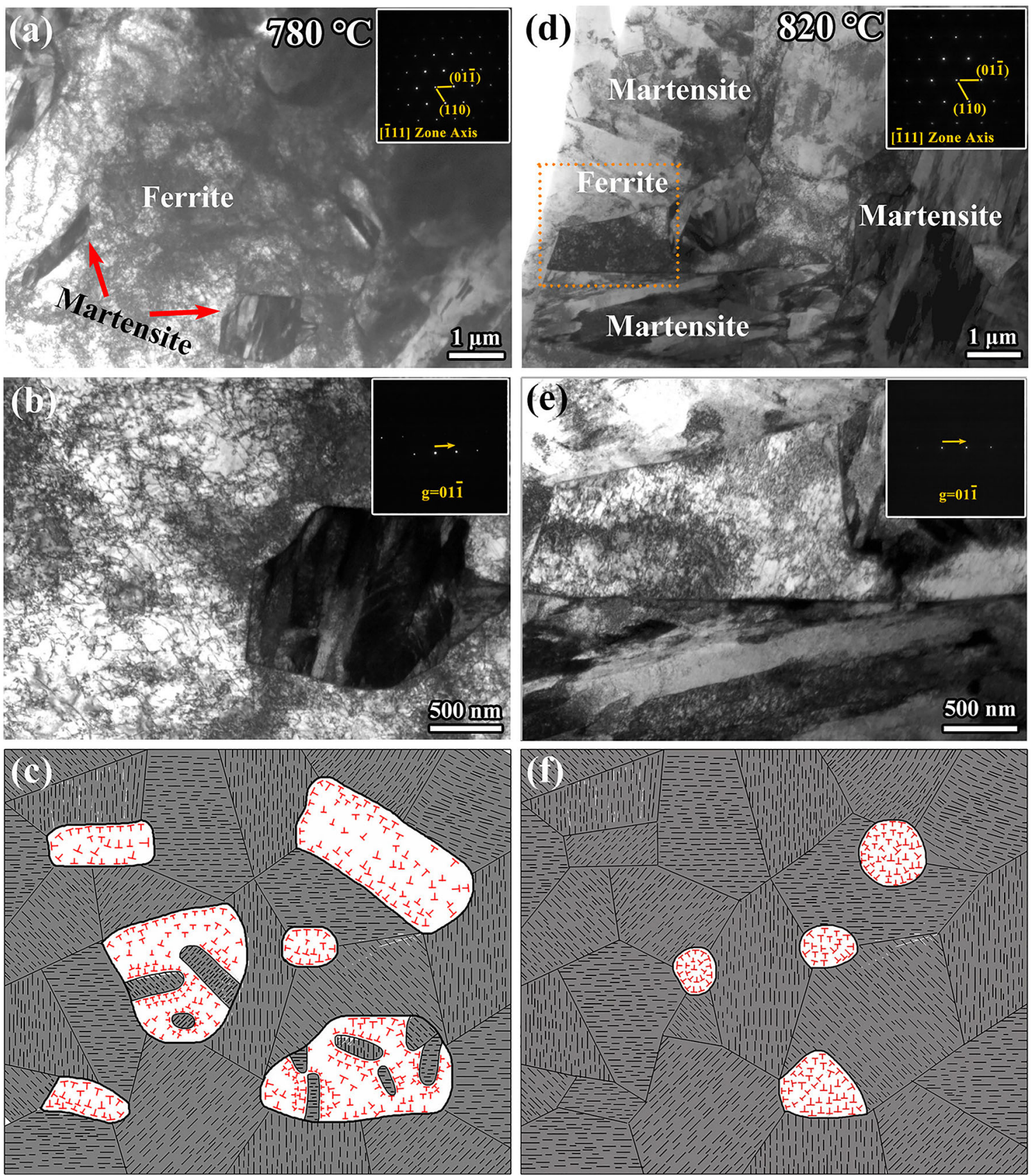

Figure 4 Microstructure of DP-780 samples with $4 \%$ tensile deformation: $\mathbf{a}, \mathbf{b}$ bright-field TEM images viewed in the twobeam condition of $g=[01 \overline{1}]$; and $\mathrm{c}$ the corresponding schematic diagram; microstructure DP-820 samples with $4 \%$ tensile

introducing high density of dislocations. However, similar to many ultra-fine-grained steels processed by plastic deformation, the cold-rolled ferrite-pearlite steel has low uniform elongation for its limited strain hardening capability [14, 40]. It is demonstrated by the engineering stress-strain curve that both the strength and ductility show a significant

deformation: $\mathbf{d}$, e bright-field TEM images viewed in the twobeam condition of $g=[01 \overline{1}]]$, and $\mathbf{f}$ the corresponding schematic diagram.

enhancement by the intercritical annealing (Fig. 5b). The DP steels annealed at $780{ }^{\circ} \mathrm{C}$ and $800{ }^{\circ} \mathrm{C}$ show a great improvement of ductility to $7.6 \%$ and $6.4 \%$, respectively. The UTS is also improved to $1.51 \mathrm{GPa}$ and 1.68 GPa after annealing. The DP steels annealed at $820^{\circ} \mathrm{C}$ and $840{ }^{\circ} \mathrm{C}$ have higher UTS of $1.74 \mathrm{GPa}$ and $1.76 \mathrm{GPa}$, respectively, and the uniform 

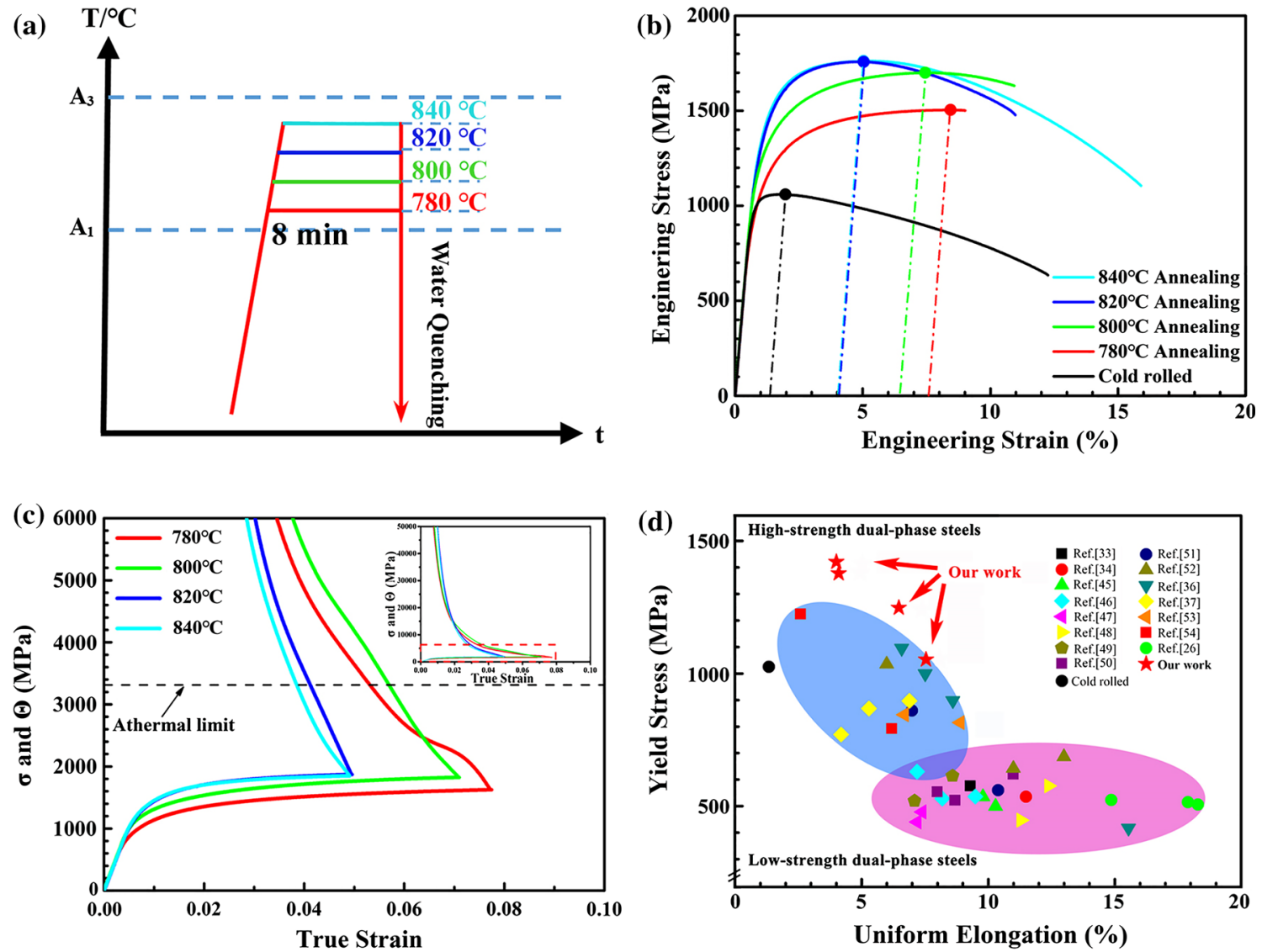

Figure 5 Processing route and mechanical properties of DP steels annealed at different temperatures: a the schematic of heat treatment procedure; $\mathbf{b}$ engineering stress-strain curves; $\mathbf{c}$ curves

elongation of these samples is about $4 \%$. The DP steels are strengthened by the introduction of strong martensite phase, and it is reasonable that the strength of DP steels is increased with increasing martensite volume fraction. But for the DP steels in this work, the martensite phase has a relatively low carbon content (from 0.26 to $0.33 \%$ ). The low-carbon martensite is highly deformable [41, 42] so that the DP steels still show appreciable ductility when high strength is achieved.

The true stress-strain curves and the corresponding evolution of strain hardening rate of the DP steels are shown in Fig. 5c. All the samples exhibit high strain hardening rate at the beginning of tensile deformation, which decreases gradually during deformation. The deformation of DP steels is closely related to two aspects: (a) a distribution of internal stresses due to the plastic incompatibility between the constituent phases; (b) GNDs are required to maintain lattice continuity between two phases. Both

of true stress and strain hardening rate; $\mathbf{d}$ tensile properties of our steel compared with those of other DP steels in the literature.

of these result in the rapid strain hardening [43, 44]. According to the Considère criterion for necking in Eq. (2), necking of the steels will occur when the stress $(\sigma)$ is larger than the strain hardening rate $(\mathrm{d} \sigma /$ $\mathrm{d} \varepsilon)$.

$\frac{1}{\sigma} \frac{\mathrm{d} \sigma}{\mathrm{d} \varepsilon}-1 \geq 0$

This criterion is also satisfied in our DP steels as shown in Fig. 5c. We compared the yield strength and uniform elongation of engineering strain of our steels to the other DP steels with a similar composition in the literature $[26,33,34,45-54]$, as shown in Fig. 5 d. High martensite volume fraction $(>60 \%)$ in our steel leads to a high yield strength, but the combination of strength and uniform elongation is superior when comparing with the high-strength counterparts. 


\section{Bauschinger effect and back stress hardening}

To understand the strengthening mechanism in the studied DP steels, the Bauschinger effect was measured by cyclic loading-unloading tests in DP-780 and DP-820. During such tests, significant unloading yield drop $\Delta \sigma$ was observed. An example is shown in the enlarged image in Fig. 6a. It has been reported that such unloading yield drop results from a unique state of deformation that is mixed by elastic deformation of martensite and plastic deformation of ferrite [55, 56]. During tensile deformation, the hard martensite stays elastic, while the soft ferrite begins to deform plastically. Upon reloading, the yield peak appears due to the load transfer between phases. Once the martensite yields, rapid relaxation of elastic stresses and strains at the phase interfaces causes the stress drop. The loading-unloading-reloading (LUR) curve shows a larger yield drop in the DP-820 sample, which is probably related to the higher martensite volume fraction [56].

The magnitude of Bauschinger effect was characterized by the back stress following the procedure in the literature [57]. The back stress was calculated according to Eq. (3) $\sigma_{\text {back }}=\frac{\sigma_{\mathrm{u}}+\sigma_{\mathrm{r}}}{2}$,

where $\sigma_{\mathrm{u}}$ and $\sigma_{\mathrm{r}}$ are the unloading yield stress and reloading yield stress, respectively. In this study, the points of $\sigma_{\mathbf{u}}$ and $\sigma_{\mathrm{r}}$ are defined by using 5\% slope reduction from the effective Young's modules according to Ref. [57]. Equation (3) is derived based on two assumptions. One is the reversible dislocation pile-up, and the other is the constant Young's modulus of the reloaded and unloaded sample. It has been demonstrated that the calculated values of back stress using Eq. (3) are less scattered, which is helpful to reduce the error of measurement. According to the relationship between back stress and effective stress $\left(\sigma_{\text {eff }}\right)[9,55-57]$, the effective stress can be obtained by detracting $\sigma_{\text {back }}$ from the flow stress $\left(\sigma_{\text {flow }}\right)$. Figure $6 \mathrm{~b}$ shows the close-up views of typical hysteresis loops of DP-780 and DP-820 samples, in which the values of $\sigma_{\mathrm{u}}$ and $\sigma_{\mathrm{r}}$ are identified for back stress calculation. As shown in Fig. $6 \mathrm{c}$ and d, both the back stresses of DP780 and DP-820 keep building up with increasing strain, and DP-820 has higher level of back stress than DP-780. Within the range of strain, the saturation of back stress was not observed, which indicates that the deformation heterogeneity keeps developing. The
Figure 6 Bauschinger effect and back stress hardening in DP-780 and DP-820: a cyclic LUR true stress-strain curves; b the close-up view of typical hysteresis loops; c evolution of $\sigma_{\text {back }}$ with true strain; d evolution of $\sigma_{\text {eff }}$ with true strain.
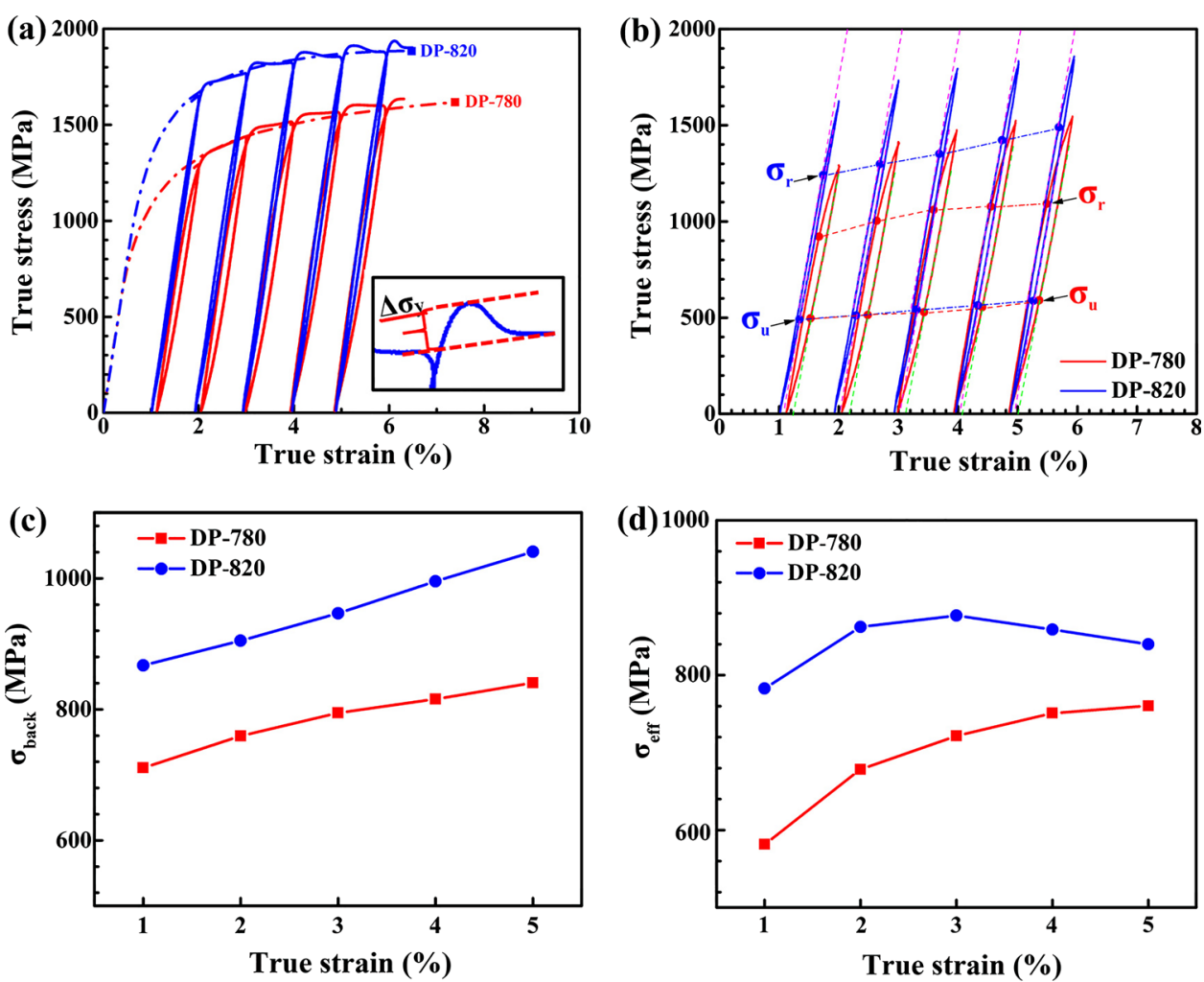
deformation heterogeneity could be at the mesoscale, and the back stress originates from the stress partitioning due to the strength contrast between ferrite and martensite [25, 58]. In addition, the deformation heterogeneity could be at the grain scale that the substructure formation involving the GNDs can result in a long-range internal stress contributing to slip resistance [49, 59]. However, in our previous TEM observations, the GND-type substructure cannot be observed, which demonstrate the significant role of mesoscale deformation heterogeneity in the previous DP steels. The higher magnitude of back stress in DP-820 than DP-780 indicates that the mesoscale deformation heterogeneity is enhanced with a higher martensite volume fraction. It is worth noting that the effective stress of DP-820 is also higher than that of DP-780. The effective stress is closely related to the forest hardening in ferrite, and the higher effective stress in DP-820 indicates that the storage of forest dislocations is enhanced when a higher volume fraction of martensite is involved. This could be explained by the argument that the plastic strain is more concentrated in the ferrite phase for the case with higher amount of strong martensite, and more dislocations are thus generated in ferrite. The above results on DP steels suggest that, for HSMs with high volume fraction of strong phase than embeds the soft phase, an improved combination of strength and ductility results from simultaneously enhanced contributions of back stress and effective stress.

\section{Conclusions}

(1) The DP steels with high volume fraction of martensite (from 64 to $83 \%$ ) were fabricated by cold rolling and intercritically annealing. Two kinds of ferrite morphologies are formed after intercritical annealing. One is the larger-sized ferritic grains $(>5 \mu \mathrm{m})$ obtained at lower temperatures (annealed at $780{ }^{\circ} \mathrm{C}$ and $800{ }^{\circ} \mathrm{C}$ ) with some intragranular martensite islands, and the other is the smaller-sized ferritic grains ( $\sim 1 \mu \mathrm{m}$ ), embedding in the martensite matrix, obtained at higher temperatures (annealed at $820^{\circ} \mathrm{C}$ and $840{ }^{\circ} \mathrm{C}$ ).
(2) Compared with the cold-rolled ferrite-pearlite steel which has a limited strength and ductility of $1.06 \mathrm{GPa}$ and $1.3 \%$, DP steels with high volume fraction of martensite exhibit a good combination of strength and ductility. The DP steels annealed at $780{ }^{\circ} \mathrm{C}$ and $800{ }^{\circ} \mathrm{C}$ show a great improving of ductility to $7.6 \%$ and $6.4 \%$, respectively, and the UTS is also improved to $1.51 \mathrm{GPa}$ and $1.68 \mathrm{GPa}$. The DP steels annealed at $820^{\circ} \mathrm{C}$ and $840{ }^{\circ} \mathrm{C}$ have higher UTS of $1.74 \mathrm{GPa}$ and $1.76 \mathrm{GPa}$, respectively, and the uniform elongation of these samples is about $4 \%$.

(3) Due to the martensite transformation of austenite during quenching, a certain number of dislocations distributed uniformly in ferritic grains in both DP-780 and DP-820. After 4\% tensile deformation, significant increase of dislocation density is found in both the DP-780 and the DP-820 samples.

(4) A heterogeneous structural material with much higher volume fraction of strong phase than embeds the soft phase is produced. The results of cyclic loading-unloading experiments indicate that the back stress of both DP-780 and DP820 keeps building up with increasing strain. And the DP-820 sample shows higher back stress and effective stress than the DP-780 sample. Significant improvement of both the strength and ductility of the DP steels results from simultaneously enhancing of back stress and effective stress.

\section{Acknowledgements}

This work is supported by the National Key R\&D Program of China (Grant Number 2017YFA0204403), the National Natural Science Foundation of China (Grant Numbers 51601094 and 51601003) and the Fundamental Research Funds for the Central Universities (Grant Number 30918011342). Q.L. thanks Fundamental Research Funds for the Central Universities (Grant Number 30917011106) for the financial support. The authors thank the Materials Characterization and Research Center of Nanjing University of Science and Technology and the Jiangsu Key Laboratory of Advanced Micro \& Nano Materials and Technology for the support. 


\section{Compliance with ethical standards}

Conflict of interest The authors declare that they have no conflict of interest.

\section{References}

[1] Kuziak R, Kawalla R, Waengler S (2008) Advanced high strength steels for automotive industry. Arch Civ Mech Eng 8:103-117

[2] Olsson K, Sperle JO (2006) New advanced ultra-high strength steels for the automotive industry. Autotechnology 6:46-49

[3] Bouaziz O, Zurob H, Huang MX (2013) Driving force and logic of development of advanced high strength steels for automotive applications. Steel Res Int 84:937-947

[4] Lu K (2014) Making strong nanomaterials ductile with gradients. Science 345:1455

[5] Wang YM, Chen MW, Zhou FH, Ma E (2002) High tensile ductility in a nanostructured metal. Nature 419:912-915

[6] Jamei F, Mirzadeh H, Zamani M (2019) Synergistic effects of holding time at intercritical annealing temperature and initial microstructure on the mechanical properties of dual phase steel. Mater Sci Eng A 750:125-131

[7] Nikkhah S, Mirzadeh H, Zamani M (2019) Improved mechanical properties of mild steel via combination of deformation, intercritical annealing, and quench aging. Mater Sci Eng A 756:268-271

[8] Zamani M, MirzadehH Maleki M (2018) Enhancement of mechanical properties of low carbon dual phase steel via natural aging. Mater Sci Eng A 734:178-183

[9] Wu XL, Yang MX, Yuan FP, Wu GL, Wei YJ, Huang XX, Zhu YT (2015) Heterogeneous lamella structure unites ultrafine-grain strength with coarse-grain ductility. Proc Natl Acad Sci USA 112:14501-14505

[10] Wu XL, Yuan FP, Yang MX, Jiang P, Zhang CX, Chen L, Wei YG, Ma E (2015) Nanodomained nickel unite nanocrystal strength with coarse-grain ductility. Sci Rep 5:11728

[11] Wu XL, Zhu YT (2017) Heterogeneous materials: a new class of materials with unprecedented mechanical properties. Mater Res Lett 5:527-532

[12] Zhou H, Huang CX, Sha XC, Xiao LR, Ma XL, Höppel HW, Göken M, Wu XL, Ameyama K, Han XD, Zhu YT (2019) In-situ observation of dislocation dynamics near heterostructured interfaces. Mater Res Lett 7:376-382

[13] Li JS, Cao Y, Gao B, Li YS, Zhu YT (2018) Superior strength and ductility of $316 \mathrm{~L}$ stainless steel with heterogeneous lamella structure. J Mater Sci 53:10442-10456. https://doi.org/10.1007/s10853-018-23224

[14] Wu XL, Yang MX, Yuan FP, Chen L, Zhu YT (2016) Combining gradient structure and TRIP effect to produce austenite stainless steel with high strength and ductility. Acta Mater 112:337-346

[15] Raeisinia B, Sinclair CW, Poole WJ, Tomé CN (2008) On the impact of grain size distribution on the plastic behaviour of polycrystalline metals. Model Simul Mater Sci Eng 16:025001

[16] Ma XL, Huang CX, Moering J, Ruppert M, Höppel HW, Göken M, Narayan J, Zhu YT (2016) Mechanical properties of copper/bronze laminates: role of interfaces. Acta Mater 116:43-52

[17] Cao Y, Wang YB, An XH, Liao XZ, Kawasaki M, Ringer SP, Langdon TG, Zhu YT (2014) Concurrent microstructural evolution of ferrite and austenite in a duplex stainless steel processed by high-pressure torsion. Acta Mater 63:16-29

[18] Cao Y, Wang YB, Alhajeri SN, Liao XZ, Zheng WL, Ringer SP, Langdon TG, Zhu YT (2010) A visualization of shear strain in processing by high-pressure torsion. J Mater Sci 45:765-770. https://doi.org/10.1007/s10853-009-3998-2

[19] Pan ZY, Gao B, Lai QQ, Chen XF, Cao Y, Liu MP, Zhou H (2018) Microstructure and mechanical properties of a coldrolled ultrafine-grained dual-phase steel. Materials 11:1399

[20] Alibeyki M, Mirzadeh H, Najafi M, Kalhor A (2017) Modification of rule of mixtures for estimation of the mechanical properties of dual-phase steels. J Mater Eng Perform 26:2683-2688

[21] Kalhor A, Mirzadeh H (2017) Tailoring the microstructure and mechanical properties of dual phase steel based on the initial microstructure. Steel Res Int 88:1600385

[22] Nakada N, Arakawa Y, Park KS, Tsuchiyama T, Takaki S (2012) Dual phase structure formed by partial reversion of cold-deformed martensite. Mater Sci Eng A 553:128-133

[23] Erdogan M (2002) The effect of new ferrite content on the tensile fracture behaviour of dual phase steels. J Mater Sci 37:3623-3630. https://doi.org/10.1023/A:1016548922555

[24] Ahmad E, Sarwar M, Manzoor T, Hussain N (2006) Effect of rolling and epitaxial ferrite on the tensile properties of low alloy steel. J Mater Sci 41:5417-5423. https://doi.org/10.10 07/s10853-006-0266-6

[25] Lai QQ, Brassart L, Bouaziz O, Gouné M, Verdier M, Parry G, Perlade A, Bréchet Y, Pardoen T (2016) Influence of martensite volume fraction and hardness on the plastic behavior of dual-phase steels: experiments and micromechanical modeling. Int J Plast 80:187-203

[26] Kalashami AG, Kermanpur A, Ghassemali E, Najafizadeh A, Mazaheri Y (2017) The effect of $\mathrm{Nb}$ on texture evolutions of 
the ultrafine-grained dual-phase steels fabricated by cold rolling and intercritical annealing. J Alloys Compd 694:1026-1035

[27] Salehi AR, Serajzadeh S, Taheri AK (2006) A study on the microstructural changes in hot rolling of dual-phase steels. J Mater Sci 41:1917-1925. https://doi.org/10.1007/s10853006-4486-6

[28] Barbier D, Germain L, Hazotte A, Gouné M, Chbihi A (2014) Microstructures resulting from the interaction between ferrite recrystallization and austenite formation in dual-phase steel. J Mater Sci 50:374-381. https://doi.org/10. 1007/s10853-014-8596-2

[29] Peranio N, Li YJ, Roters F, Raabe D (2010) Microstructure and texture evolution in dual-phase steels: competition between recovery, recrystallization, and phase transformation. Mater Sci Eng A 527:4161-4168

[30] Zheng CW, Raabe D (2013) Interaction between recrystallization and phase transformation during intercritical annealing in a cold-rolled dual-phase steel: a cellular automaton model. Acta Mater 61:5504-5517

[31] Nouroozi M, Mirzadeh H, Zamani M (2018) Effect of microstructural refinement and intercritical annealing time on mechanical properties of high-formability dual phase steel. Mater Sci Eng A 736:22-26

[32] Mirzadeh H, Alibeyki M, Najafi M (2017) Unraveling the initial microstructure effects on mechanical properties and work-hardening capacity of dual-phase steel. Metall Mater Trans A 48:4565-4573

[33] Son Y, Lee YK, Park K-T, Lee CS, Shin DH (2005) Ultrafine grained ferrite-martensite dual phase steels fabricated via equal channel angular pressing: microstructure and tensile properties. Acta Mater 53:3125-3134

[34] Kyung-Tae P, Kook L, Hyuk S (2005) Fabrication of ultrafine grained ferrite/martensite dual phase steel by severe plastic deformation. ISIJ Int 45:750-755

[35] Lai QQ, Gouné M, Perlade A, Pardoen T, Jacques P, Bouaziz O, Bréchet Y (2016) Mechanism of austenite formation from spheroidized microstructure in an intermediate $\mathrm{Fe}-0.1 \mathrm{C}-$ 3.5Mn steel. Metall Mater Trans A 47:3375-3386

[36] Sharma S, Nanda T, Adhikary M, Venugopalan T, Ravi Kumar B (2016) A simulation study of pearlite-to-austenite transformation kinetics in rapidly heated hot-rolled low carbon steel. Mater Des 107:65-73

[37] Ashrafi H, Shamanian M, Emadi R, Saeidi N (2017) Correlation of tensile properties and strain hardening behavior with martensite volume fraction in dual-phase steels. Trans Indian Inst Met 70:1575-1584

[38] Zhao ZZ, Tong TT, Liang JH, Yin HX, Zhao AM, Tang D (2014) Microstructure, mechanical properties and fracture behavior of ultra-high strength dual-phase steel. Mater Sci Eng A 618:182-188

[39] Davies RG (1979) Early stages of yielding and strain aging of a vanadium-containing dual-phase steel. Metall Trans A 10:1549-1555

[40] Cao Y, Ni S, Liao XZ, Song M, Zhu YT (2018) Structural evolutions of metallic materials processed by severe plastic deformation. Mater Sci Eng R 133:1-59

[41] Lai QQ, Sinclair CW, Poole WJ (2018) The anisotropic kinetics of strain aging in a martensitic steel. Can Metall Q 57:20-27

[42] Allain S, Bouaziz O, Takahashi M (2012) Toward a new interpretation of the mechanical behaviour of as-quenched low alloyed martensitic steels. ISIJ Int 52:717-722

[43] Kalashami AG, Kermanpur A, Najafizadeh A, Mazaheri Y (2016) Development of a high strength and ductile Nbbearing dual phase steel by cold-rolling and intercritical annealing of the ferrite-martensite microstructures. Mater Sci Eng A 658:355-366

[44] Etesami SA, Enayati MH, Kalashami AG (2017) Austenite formation and mechanical properties of a cold rolled ferritemartensite structure during intercritical annealing. Mater Sci Eng A 682:296-303

[45] Park KT, Han SY, Ahn BD, Shin DH, Lee YK, Um KK (2004) Ultrafine grained dual phase steel fabricated by equal channel angular pressing and subsequent intercritical annealing. Scr Mater 51:909-913

[46] Das D, Chattopadhyay P (2009) Influence of martensite morphology on the work-hardening behavior of high strength ferrite-martensite dual-phase steel. J Mater Sci 44:2957-2965. https://doi.org/10.1007/s10853-009-3392-0

[47] Calcagnotto M, Ponge D, Raabe D (2010) Effect of grain refinement to $1 \mu \mathrm{m}$ on strength and toughness of dual-phase steels. Mater Sci Eng A 527:7832-7840

[48] Calcagnotto M, Adachi Y, Ponge D, Raabe D (2011) Deformation and fracture mechanisms in fine- and ultrafinegrained ferrite/martensite dual-phase steels and the effect of aging. Acta Mater 59:658-670

[49] Calcagnotto M, Ponge D, Demir E, Raabe D (2010) Orientation gradients and geometrically necessary dislocations in ultrafine grained dual-phase steels studied by $2 \mathrm{D}$ and $3 \mathrm{D}$ EBSD. Mater Sci Eng A 527:2738-2746

[50] Hamid A, Militzer M, Poole W (2011) Formation of ultrafine grained dual phase steels through rapid heating. ISIJ Int 51:958-964

[51] Papa Rao M, Subramanya Sarma V, Sankaran S (2017) Microstructure and mechanical properties of $\mathrm{V}-\mathrm{Nb}$ microalloyed ultrafine-grained dual-phase steels processed through severe cold rolling and intercritical annealing. Metall Mater Trans A 48:1176-1188 
[52] Papa Rao M, Subramanya Sarma V, Sankaran S (2013) Development of high strength and ductile ultra fine grained dual phase steel with nano sized carbide precipitates in a V$\mathrm{Nb}$ microalloyed steel. Mater Sci Eng A 568:171-175

[53] Saeidi N, Ashrafizadeh F, Niroumand B (2014) Development of a new ultrafine grained dual phase steel and examination of the effect of grain size on tensile deformation behavior. Mater Sci Eng A 599:145-149

[54] Sun JJ, Jiang T, Sun Y, Wang YJ, Liu YN (2017) A lamellar structured ultrafine grain ferrite-martensite dual-phase steel and its resistance to hydrogen embrittlement. J Alloys Compd 698:390-399

[55] Yang MX, Yuan FP, Xie QG, Wang YD, Ma E, Wu XL (2016) Strain hardening in $\mathrm{Fe}-16 \mathrm{Mn}-10 \mathrm{Al}-0.86 \mathrm{C}-5 \mathrm{Ni}$ high specific strength steel. Acta Mater 109:213-222

[56] Ma Y, Yang MX, Jiang P, Yuan FP, Wu XL (2017) Plastic deformation mechanisms in a severely deformed $\mathrm{Fe}-\mathrm{Ni}-\mathrm{Al}-$ C alloy with superior tensile properties. Sci Rep 7:15619
[57] Yang MX, Pan Y, Yuan FP, Zhu YT, Wu XL (2016) Back stress strengthening and strain hardening in gradient structure. Mater Res Lett 4:145-151

[58] Pierman AP, Bouaziz O, Pardoen T, Jacques PJ, Brassart L (2014) The influence of microstructure and composition on the plastic behavior of dual-phase steels. Acta Mater 73:298-311

[59] Kadkhodapour J, Schmauder S, Raabe D, Ziaei-Rad S, Weber U, Calcagnotto M (2011) Experimental and numerical study on geometrically necessary dislocations and non-homogeneous mechanical properties of the ferrite phase in dual phase steels. Acta Mater 59:4387-4394

Publisher's Note Springer Nature remains neutral with regard to jurisdictional claims in published maps and institutional affiliations. 